Proceedings of the Institution of Mechanical Engineers Part B-Journal of Engineering Manufacture, September 1, 2009, vol. 223, no. 9, pp1085-1096

\title{
Zero Carbon Manufacturing Facility - towards integrating material, energy and waste process flows
}

\author{
P D Ball*, S Evans, A Levers, and D Ellison \\ Department of Manufacturing, Cranfield University, Cranfield, UK
}

\begin{abstract}
The increasing pressure on material availability, energy prices as well as emerging environmental legislation is leading manufacturers to adopt solutions to reduce their material and energy consumption as well as their carbon footprint, thereby becoming more sustainable. Ultimately manufacturers could potentially become zero carbon by having zero net energy demand and zero waste across the supply chain. Literature on zero carbon manufacturing, and the technologies that underpin it, is growing but there is little available on how a manufacturer undertakes the transition. Additionally, the work in this area is fragmented and clustered around technologies rather than around processes that link the technologies together. There is a need to better understand material, energy and waste process flows in a manufacturing facility from a holistic viewpoint. With knowledge of the potential flows, design methodologies can be developed to enable zero carbon manufacturing facility creation. This paper explores the challenges faced when attempting to design a zero carbon manufacturing facility. A broad scope is adopted from legislation to technology and from low waste to consuming waste. A generic material, energy and waste flow model is developed and presented to show the material, energy and waste inputs and outputs for the manufacturing system and the supporting facility and, importantly, how they can potentially interact. Finally the application of the flow model in industrial applications is demonstrated to select appropriate technologies and configure them in an integrated way.
\end{abstract}

\section{Keywords}

Zero carbon manufacturing, low carbon, sustainable manufacture, process mapping

\section{Introduction}

Environmental impact is now a common topic of discussion in manufacturing businesses. This is in part drawn from the growing evidence of global warming, in part from emerging legislation and in part from the growing financial impact. This financial impact comes from material, energy and waste costs as well as from the punitive costs from lack of compliance. Another way of expressing this is the growing interest in the three legs of the triple bottom line (3BL) concept of People, Planet and Profit, i.e. social equity, environmental quality, and economic prosperity [1].

Manufacturing and service companies are experiencing a growing impact from the changes. Energy prices have risen considerably in recent years and the forecasts suggests this trend

* Corresponding author: Department of Manufacturing, Cranfield University, Building 50, Cranfield, Beds MK43 OAL, UK. email: p.d.ball@cranfield.ac.uk 
will continue as oil output reaches a peak and demand outstrips supply. Additionally manufacturing is seeing pressures from material costs and scarcity. For example, steel price and consumption have doubled over the last 10 years [2], waste disposal costs are rising (UK landfill tax will double by 2010/11 [3]) and there are concerns over security of material supplies [4]. Manufacturing companies are therefore being squeezed by both the cost of their material and energy inputs as well as their waste outputs. Reducing the carbon impact, and cost, of manufacturing inputs and outputs is a priority and is likely to become increasingly important with the introduction of carbon trading systems such as the EU Emission Trading Scheme (ETS). Further, according to DTI [5], buildings account for $50 \%$ of UK carbon emissions and the UK's 2008 budget [6] expressed the ambition for all new non-domestic buildings to be zero carbon by 2019. Apart from legislation and that reducing material and energy use being simply good economic sense, it is also responsible corporate practice.

Piecemeal approaches will reduce carbon impact but it is only by adopting a holistic approach that zero carbon manufacture could be achieved. There is a need to extend the general principle of remove, reduce, reuse and recycle that is applied materials and to apply it to energy as well. For example, reducing energy use for heating could be achieved by better thermal efficiency, in the extreme the thermal efficiency and reuse of energy could be so high that it could remove the need for boilers for facility heating. So by using more renewable energy, increasing the efficiency of energy use and creating less waste the net carbon impact of a manufacturing facility can approach zero. When designing manufacturing systems there is huge potential to think more fundamentally about these areas and to engage staff and the community.

There has been a dramatic growth in research on sustainable production [7] and the manufacturing community is thinking about zero carbon but there are few if any integrated tool-sets for them to use. This paper explores the gap between available low carbon approaches and technologies and how they are linked together to form an integrated approach to zero carbon. The paper presents the concept of an integrated material, energy and waste flow model that charts the generic lifecycle of material, energy and waste flows in a manufacturing facility. These flows can then be used as a way of integrating approaches and technologies together for adapting the existing facilities through to re-building. Whilst the paper will present how the material, energy and waste flow model can be applied, it is also concerned with the challenges and thinking of the zero carbon journey as much as the process tool to support that journey.

\section{Embarking on journey to zero carbon}

Is zero carbon about reducing carbon emissions from fossil fuel use or reducing energy use? Is zero carbon about reducing landfill or reducing material use? Zero carbon manufacturing spans a plethora of issues ranging from material and energy inputs, to the efficiency of manufacturing systems and facilities, to the waste output and supply chain movements. We view zero carbon manufacturing as being "a sustainable approach to manufacturing, which has zero net energy demand and zero material waste across the supply chain". As will be seen, zero carbon demands that an integrated, systems approach is taken.

The principle of sustainable manufacture is to meet the needs of the current generation without compromising the ability of future generations to meet their own needs [8]. 
Operational methods for the minimisation of energy use in manufacturing have been studied [e.g. 9]. Pre-dating sustainability research are the waste reduction principles embedded in the Toyota Production System [10]. Additionally there has been a particular growth in literature on manufacture for re-use [11]. Despite this, the literature is lacking in how these components of zero carbon manufacture can be brought together in an integrated way.

There are a number of levels at which this area could be considered. Firstly the design or modification of the product can have a significant impact on the material and energy use both in manufacture and throughout the rest of the life cycle. Secondly there are the manufacturing processes that are utilised across the value chain to fabricate and assemble the product impacting on the beginning of life phase of a product. Additionally there is the facility design or modification to consider and how the 'shed' that is wrapped around the manufacturing facility contributes to the energy used in production.

There are many publications on product design and the life cycle view [e.g. 12, 13, 14, 15]. In a small number of industries, aerospace and automotive sectors in particular, the design of single product is likely to have a very significant impact on the overall manufacturing system design and the supporting facility. In majority of other industries the manufacturing system, its processes, its supply chain and the supporting facilities evolve over time through progressive iterative and very occasional major changes. Major facility and manufacturing system changes can occur independently of product design activity. Any product design or modification decision is likely to have an impact on the manufacturing system and facility but typically this is cumulative effect over many years. Whilst it is possible to consider these independently, this paper focuses on an integrated view of manufacturing systems and facilities that is cognisant of the design influence. In particular, there areas for potential development of manufacturing systems and facilities to progress towards zero carbon manufacturing that are not prompted by design activity.

Metrics exist for measuring carbon impact and many companies are activity engaged in measuring their carbon use and instigating programmes to reduce the impact. But whilst metrics exist a hurdle that must be overcome is that manufacturing system design and improvement approaches are lagging current awareness and drivers in sustainable activities; Manufacturing system design approaches [e.g. 16, 17, 18] pre-date the growth of sustainable manufacturing thinking.

Manufacturing systems (industrial systems) design focuses on flow and efficiency with performance metrics that include cost, quality and delivery. Importantly, the flow analysis typically focuses on the forward product material flow and neglects other material flows and waste streams. Significantly, energy use is typically not a metric that is employed in manufacturing systems design. Facility design is typically considered independently of the design of the manufacturing system. In the case of new facilities a 'shed' is typically designed around the required manufacturing system footprint rather than as an integral resource to draw on for energy input and to reuse excess energy. In the case of manufacturing system redesign, the facility fabric and systems are rarely modified or upgraded. With no integrated view, design challenges are viewed at a local level rather than in an enterprise context. Improvement approaches for existing systems, for example those based around Value Stream Mapping, are similarly deficient. This misses important opportunities for innovative solutions to achieve zero carbon manufacturing. 
By examining manufacturing systems and their facility/infrastructure together, we move away from focusing on the individual design and improvement tasks or manufacturing technology deployment and move towards an integrated view of the various lifecycles of: Material, energy and waste flows, building lifecycle and manufacturing systems lifecycle. Thus the challenge for manufacturing requires supporting thinking and tools that integrate such key flows.

\section{Research design}

The work reported in this paper is part of a wider programme of research with the aim "to develop an approach to guide the design of zero carbon manufacturing facilities". Specific objectives of the research are to establish current thinking on technological solutions and how they are integrated, establish the requirements of zero carbon manufacture and ascertain the viability of using material, energy and waste flow modelling as a basis for supporting zero carbon manufacturing facility design or improvement. The particular research question addressed by the work reported here is:

$R Q$. Can modelling material, energy and waste flows form the foundation for zero carbon manufacturing facility design?

The field of zero carbon manufacturing is fragmented and as yet there are no unifying theories, frameworks or models. The research approach is therefore exploratory and inductive using case work from which theory can be built and tested. The case methodology is appropriate given the loose nature of the research field [19].

The data collection approach must reflect the emerging and fragmented nature of the field. Literature from peer reviewed sources is an obvious choice but the data collection needs to be broad to capture emerging thinking from expert interviews (practitioner and academic), company visits and trade events. The data collection must treat technologies as a 'black box'; central to this is what technologies are available and their inputs and outputs rather than their functional capabilities. The data collection feeds into the analysis phase that aims to link approaches, tools and technologies together rather than attempt to further advance individual technologies. The analysis is therefore carried out with a process mindset, aiming to bring together the silos to deliver an integrated process view of zero carbon manufacturing. It will be seen later that process maps of a manufacturing enterprise documenting material, energy and waste flows were created. These were developed from considering the inputs and outputs of each process and how they could link together in a manufacturing business.

\section{Zero carbon manufacturing approaches}

The term zero carbon manufacturing is used here to include the production system, the supporting infrastructure (including offices and facilities) as well as the interface with the supply chain and community. Whilst new design activities and facility location will have significant influence on these areas they are omitted in order to provide a foundation on which to base a discussion on the typical scope of influence of a manufacturing operation and the associated design and improvement activities .

There is a huge range of potential solutions to help a manufacturer to approach zero carbon. Wind turbines and solar PV panels are candidates that may immediately come to mind. These technologies can be utilised but it is argued here that it is better to think in clusters of 
"know how", combining the technologies with the approaches and linking them together. Also, there is greater potential benefit in considering how energy is used rather than how 'clean' it is.

The available literature on zero carbon, green, sustainable and environmentally-friendly manufacture is vast but its maturity is still forming. Additionally, it sits within discipline clusters rather than following the life cycle of the key influences on zero carbon manufacturing, namely material, energy and waste. For example, the lifecycle principle of cradle to grave is well understood, however, the principle of cradle to cradle [20] has yet to gain wider acceptance and adoption. The cradle to cradle philosophy is based on separating key material flows so that materials can constantly be reused rather than down-cycled and eventually lost in incineration or landfill as is the case for most materials now. The following discussion is based on a combination of literature review and primary data collection through company visits, events and academic and industry experts. Much is based around technology but the importance is placed on how that technology (or clusters of "know how") are combined through a systems viewpoint.

Conventional renewable energy technologies are often the first to be examined when considering zero carbon approaches. Wind turbines, solar heat and solar PV have been well publicised. Initial suitability of these technologies can be quickly gained from wind and solar maps. Solar PV is relatively costly currently but technological advances and economics means that large solar PV panels, including for retrofit, could be a viable option within 5 years. Hydro and emerging tidal and wave technologies exist and, as with wind, can be utilised via the national grid. Thinking of technologies in isolation limits the overall benefit. It is simply not enough to switch a fossil fuel source of energy to a renewable one. Energy sources are separate to the efficiency of their use. For example, using ground source heat pumps to provide low grade heat for under floor heating combines a renewable technology with efficient energy utilisation. Renewable technologies such as wind turbines are not strictly part of a manufacturing facility, however, are included due to the potential for direct net carbon reduction as well as their impact on the facility, e.g. intermittency.

Moving from the source of energy to the use of energy, manufacturing processes are the next area to consider. Manufacturing processes consume significant amounts of materials and energy and in turn create significant waste. Lean [21] techniques may be considered to be sufficient here due to their focus on value adding activities and the removal of waste. The removal of waste is compatible with the greening of manufacture and reduction in environmental impact [22]. Activities may range from reducing inventory and thereby reducing potential obsolescence, to replacing inefficient motors with more efficient ones. However, considering the manufacturing processes in isolation risks missing wider benefits. Taking compressed air for example, up to $10 \%$ of the energy supplied to UK industry is used to compress air and up to $80 \%$ of the energy used in compressing air could be re-used for lowgrade space heating or heating water [23]. Given that as little of $10 \%$ of the energy supplied to a compressor may be converted into useful energy [23] alternatives to compressed air could be sought. Viewing the manufacturing processes as an integral element of a larger system is necessary to get such benefits. For this reason, the research does not consider the detail of individual manufacturing processes. Treating individual processes as 'black boxes' forces a systems view of the inputs and outputs of a process that is so rarely considered. For example, reducing resource and energy consumption in a painting process is a commendable activity, but reducing it to zero is unachievable. However, treating the subsequent waste 
water and energy outputs from a paint plant as potential inputs elsewhere rather than simply as wastes to be managed offers potential overall savings.

Moving beyond the manufacturing system, the supply chain must be considered both upstream and downstream. At an operational level, the transport of goods from the supplier to the facility and from the facility to the customer can be a significant source of carbon emission depending on the distance travelled and the mode of transport used. This is potentially a significant issue given the growth of outsourcing and especially off-shoring. Additionally the type of packaging must be considered. At a more tactical level, studies show how different companies collaborate with their suppliers. Major companies such as Boeing and Nissan use standards like ISO 14001 to set environmental targets across their supply chain. Although ISO 14001 has become a de facto framework for environment management systems, it is not a panacea as it does not specify clear targets or guidelines. At a more strategic level the overall supply chain configuration covering the choice of suppliers and the interaction with them would be considered. Many authors have investigated the 'greening' of the supply chain [e.g. 24, 25, 26] covering performance measurement through to the treatment of 'waste' (reduction/reduce, reuse, remanufacture, recycle and dispose). Additionally, the well established Supply Chain Operations Reference (SCOR) model is being adapted to incorporate environmental management in the form of GreenSCOR [27].

There is increasing attention being paid to converting waste into energy. Interestingly, the fuel for this type of energy can be stored and does not have the problem of intermittency. Biomass includes energy crops as well as organic waste that can be used for energy generation purposes. Technologies include anaerobic digestion, gasification and pyrolysis. Moving from technologies to clusters of "know how" leads to better overall solutions, such as taking appropriate community waste as an input to energy generation, thus reducing the problem of community waste and obtaining a low cost source of energy.

There are a number of technologies that are specific to construction of facilities that can have a significant impact on material and energy use. These technologies could be used when there are significant modifications to a facility or a new facility is built. Utilising sunlight for both energy generation as well as indirect light is a powerful approach, not just to reduce net energy demands but high light levels have been shown to reduce absenteeism, increase productivity, maintain health and increase attentiveness [28]. Additionally it is claimed that the carrying cost of people (recruiting, employing and retaining) is a hundred times greater than the carrying cost of the average building [20]. Ventilation typically requires energy but passive ventilation approaches exist as well as heat recovery from spent air. At a very basic level, the greater use of windows that can also be opened may be a more cost effective way at providing light and ventilation than electric lighting and forced ventilation and air conditioning. Rainwater collection from the facility roof can also be used as grey water for sanitation as well as for all other uses following treatment.

Engaging with the community and developing Corporate Social Responsibility (CSR) [29] are not zero carbon approaches per se, but the thinking and values within a company can be spread into the local community for overall benefit such as influencing recycling and commuting behaviours. Ultimately the interaction between a manufacturer and the local community could be considered at a very high level of systems thinking, where waste from the community or heat from the manufacturer could be exchanged with one another. 
This section has given a broad, high level view of a selection from the components that can make up zero carbon or sustainable manufacturing systems in the widest form. The components alone will give benefit but, as the next section demonstrates, the integration of these components enables further benefits.

\section{Integrated view}

Modelling is a technique that can capture the complexity and interactions of a system to enable it to be more easily understood. Modelling can range from simple static documentation of process sequences to powerful computer based discrete event simulation approaches that capture the time varying, stochastic nature of processes. The static documentation of processes can be carried out using various techniques including flowcharts, data flow diagrams, GRAI grids and IDEF. Whilst each technique has its unique strengths, they are all able to capture complexity of interactions of activities and can be used as a catalyst for ideas and innovation.

Modelling is an appropriate technique therefore on which to take an integrated view of manufacturing for the pursuit of zero carbon. It has the potential to capture diverse activities including production, community and energy from waste. Inter-linking these diverse activities could be achieved by tracing the material, energy and waste flows associated with each activity and identifying opportunities for the outputs of one activity to form the inputs of another. It is accepted that the material inputs and outputs of production directly link to supply chain activities but less obvious is whether production waste is a loss from the entire system or an input to another activity. The advantage of process modelling is that it moves the focus from activity (which could be a low carbon technology) to the interaction of activities.

Value Stream Mapping (VSM) [21] is an established and valued technique in manufacturing. VSM allows a manufacturer's material and information flows from customer demand through to suppliers to be represented pictorially to engage staff in examining their process holistically and in turn identifying waste. VSM has a number of key attributes, namely:

- it allows simplification and focus in complex scenarios;

- it views the entire flow not just individual conversion activities;

- it moves away from resource utilisation focus;

- it is readily used to engage staff in improvement activities;

- it can lead to counter-intuitive findings but systems thinking makes it a rational choice, e.g. reducing inventory in a system improves performance.

The VSM concept has potential for use in zero carbon thinking but not in its current form. VSM is applied to the primary material flows of the value adding processes and although waste in its many forms is documented, the lifecycle of material waste is incomplete. Additionally it typically ignores the support processes and the energy flows. However, if the VSM concept and use was widened to include the full material, energy and waste flows the process modelling concept could be used in the same way as VSM is now used to engage staff and focus on waste in its widest form. Thus flows would not only include the value adding processes but the support (facility) processes also. Like with VSM now, a wider view of process mapping could enable it to be used as a catalyst for ideas and innovation for zero carbon manufacturing. 
Modelling the flows for the manufacturing system and the facility holistically allows the materials, energy and waste output from one activity to be utilised by another. At a detailed level it could be used to question why heat from air conditioning (perhaps used to cool a server room) is expelled into the atmosphere but independently more energy is used to heat office space. On a larger scale, low grade heat could be captured from energy intensive manufacturing processes for under floor heating and organic waste could be used for energy generation.

Industrial ecology seeks to optimise the life cycle of virgin materials through to ultimate disposal in the pursuit of sustainable manufacture [30]. Here each process is dependent and interrelated to the wider system and opportunities are sought to reuse and recycle materials within a system rather than allow them to leave as waste (noting that most 'recycling' today is actually 'down-cycling' as the resulting material is of inferior quality [20]). Examples range from the reuse of materials in precious metals supply chains through to product service systems [31] in which the product is retained by the manufacturer to provide a service such as the models operated by Xerox and Rolls-Royce plc. Life cycle management approaches are being developed for sustainable manufacturing [32] that examine the product from concept to re-use/end of life, but these often focus on the life of the product rather than the manufacturing facility. Such approaches can provide a vision and framework to proceed but more detail is needed on the material and energy flows.

There are examples of work on modelling sustainable production. For example a case study of a bicycle manufacturer in China where water, energy and solvent pinch analysis [33] was used to examine energy flows in the painting and drying processes independently which then resulted in one process pre-heating the air intake for the others.

Whilst industrial ecology takes a top down view of a system and VSM takes a bottom up view, there is no single framework or process reference model that encompasses all the material, energy and wastes flows from a manufacturing perspective. There are, however, many examples of companies using the waste outputs of one process as an input to other processes:

- Toyota Motor Manufacturing UK use treated waste water discharged from their painting process for their boilers and compressors and has separately invested in rainwater harvesting [34].

- Conoco Phillips Immingham combined-heat-and-power (CHP) plant supplies heat and electricty to oil refineries using natural and waste gas from the refineries, thereby reducing the fuel input and carbon output [35].

- IBM in Switzerland have linked a data centre to a swimming pool [36]. The data centre will produce up to $2,800 \mathrm{MW}$ in wasted heat per year. Instead of using even more energy to dissipate the excess heat it is cooled using a connection to a swimming pool (or rather the swimming pool is heated using the data centre's waste heat). Whilst not manufacturing or within the immediate physical perimeter of the premises, this example shows how the energy output of one process is used effectively in the community.

These are examples of companies taking a systems view of their process flows and recovering and reusing waste and energy to reduce cost and environmental impact. These examples represent snap shots of localised improvement activities. The same principles could be achieved across a whole facility but there is a lack of guidance and reference 
processes to assist manufacturing companies. The next section introduces generic material, energy and waste flow modelling and demonstrates how it can be applied.

\section{Application of the material, energy and waste process flow concept}

In this section the application of the material, energy and waste flow concept will be presented. The modelling approach will be described, and the generic flow model derived from primary case research is presented together with examples illustrating its operational viability.

The areas covered in the earlier review of zero carbon approaches and technologies are a combination of core manufacturing activities and general technologies or mechanisms. Additionally, emerging legislation is having a significant impact on this area. In creating flow models of this area, the IDEF0 format is well suited. Each activity in an IDEF0 model has inputs entering on the left, outputs leaving on the right, mechanisms feeding from below and controls or policies from above. This can be illustrated in Figure 1 which shows the potential for modelling the material, energy and waste flows. Here a number of energy inputs are converted into 'green' energy output using a number of mechanisms and a number of controls. Whilst it could be argued the generation of energy is outside the scope of manufacturing activities, most of the outputs and many of the inputs shown in Figure 1 are supplied from and delivered to manufacturing operations. 


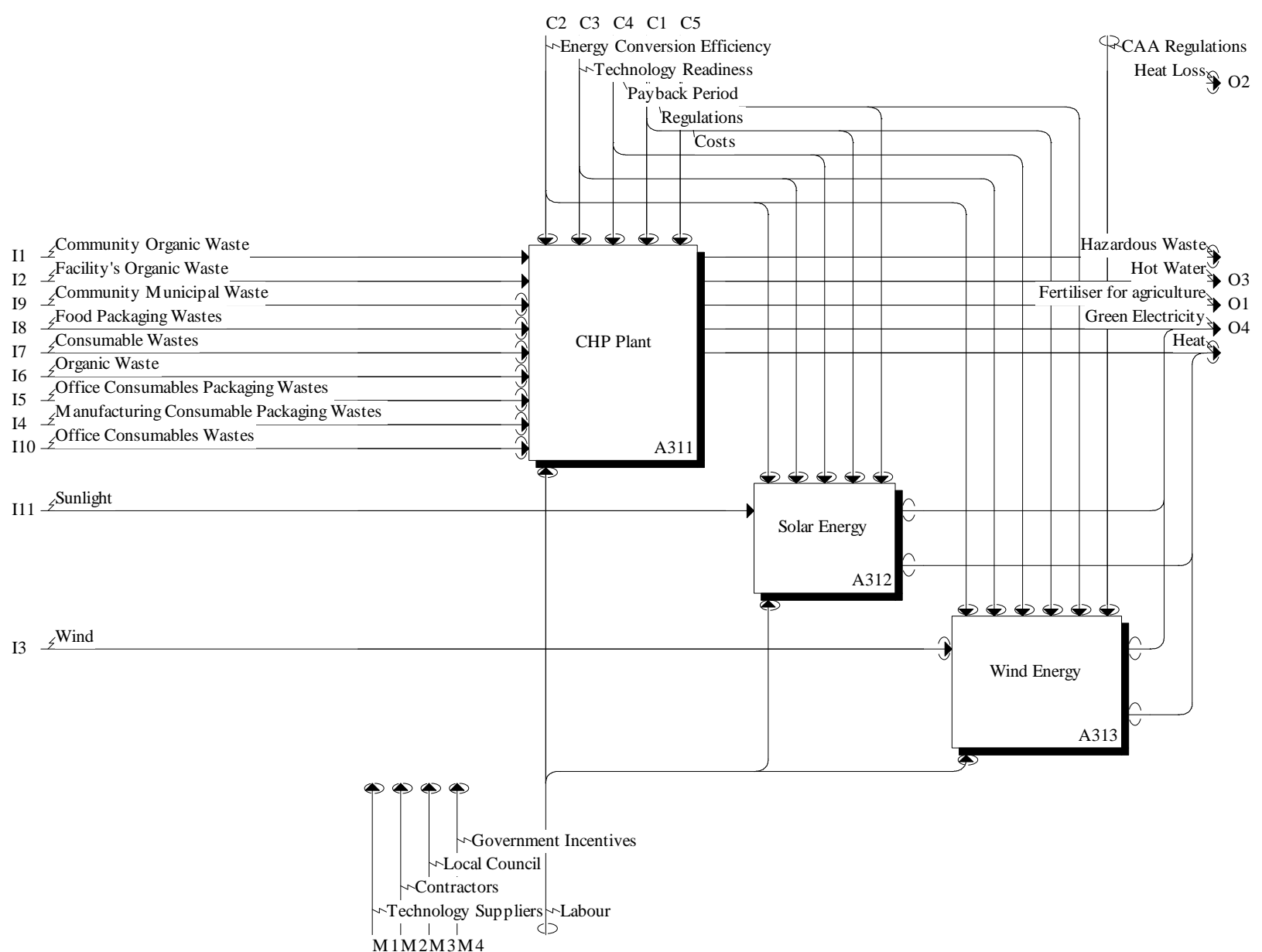

Figure 1. The concept of modelling material, energy and waste flows applied to renewable energy sources for facility

Figure 2 shows how this concept can be extended wider for other utility supplies into the manufacturing system. The figure shows how renewable energy sources (as well as grid electricity) enter the system leave in a different form, e.g. 'green' electricity'. Another flow to highlight is grey water entering the system and being processed for use as cooling and heating water. 


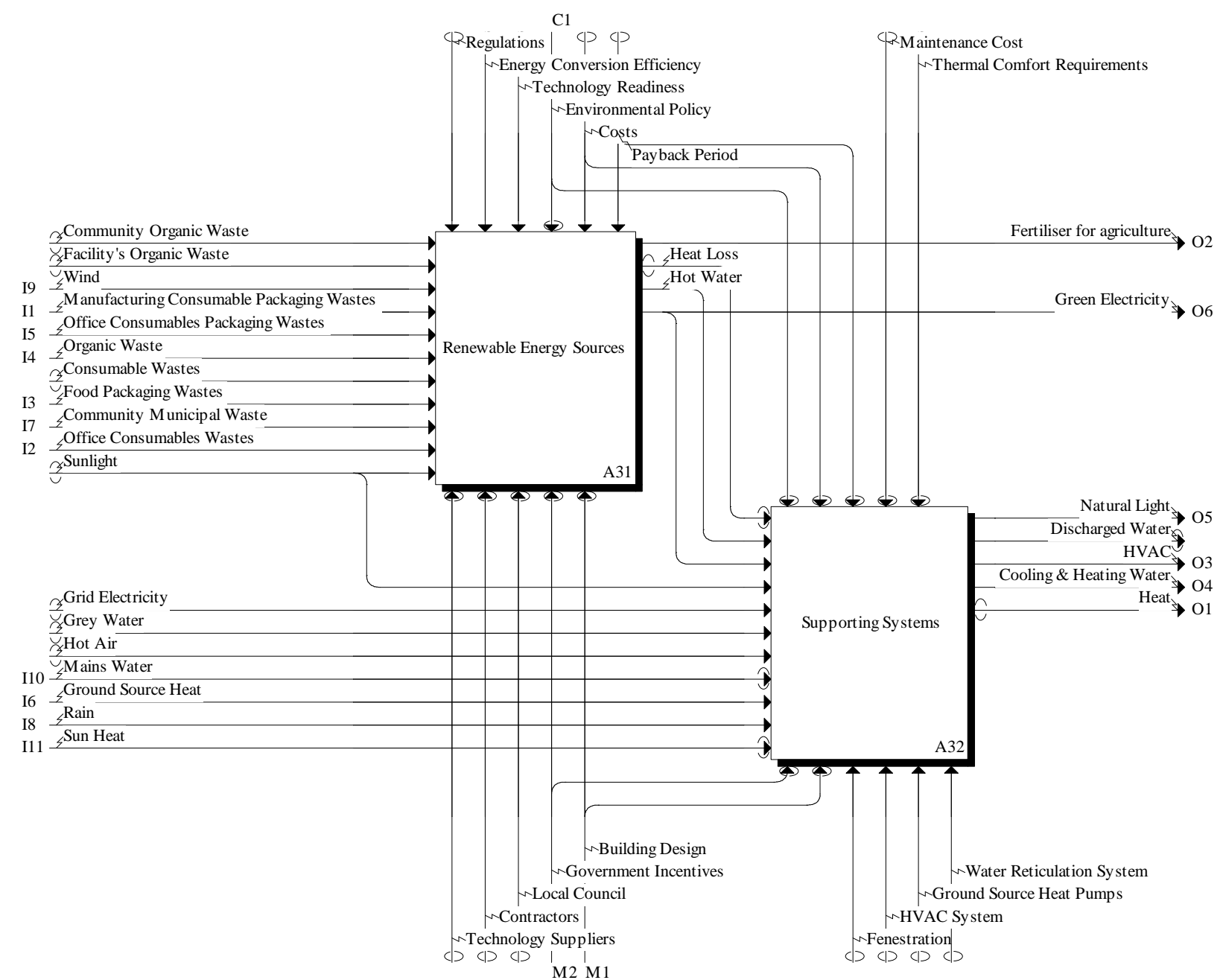

Figure 2. Utility supply flow modelling

The approach is hierarchical. The activities A12 and A13 in Figure 2 are in turn decomposed into more and more detail. So far it is only the utilities supply to the manufacturing system that has been presented and not the manufacturing system itself. Figure 3 illustrates the wider application of the concept to the manufacturing system, workforce, community and utilities of a manufacturing enterprise. As before, each of these activities is in turn decomposed into more detailed activities and flows. The flow model shows how inputs into utilities such as community waste are converted to outputs that become inputs to the manufacturing system. 


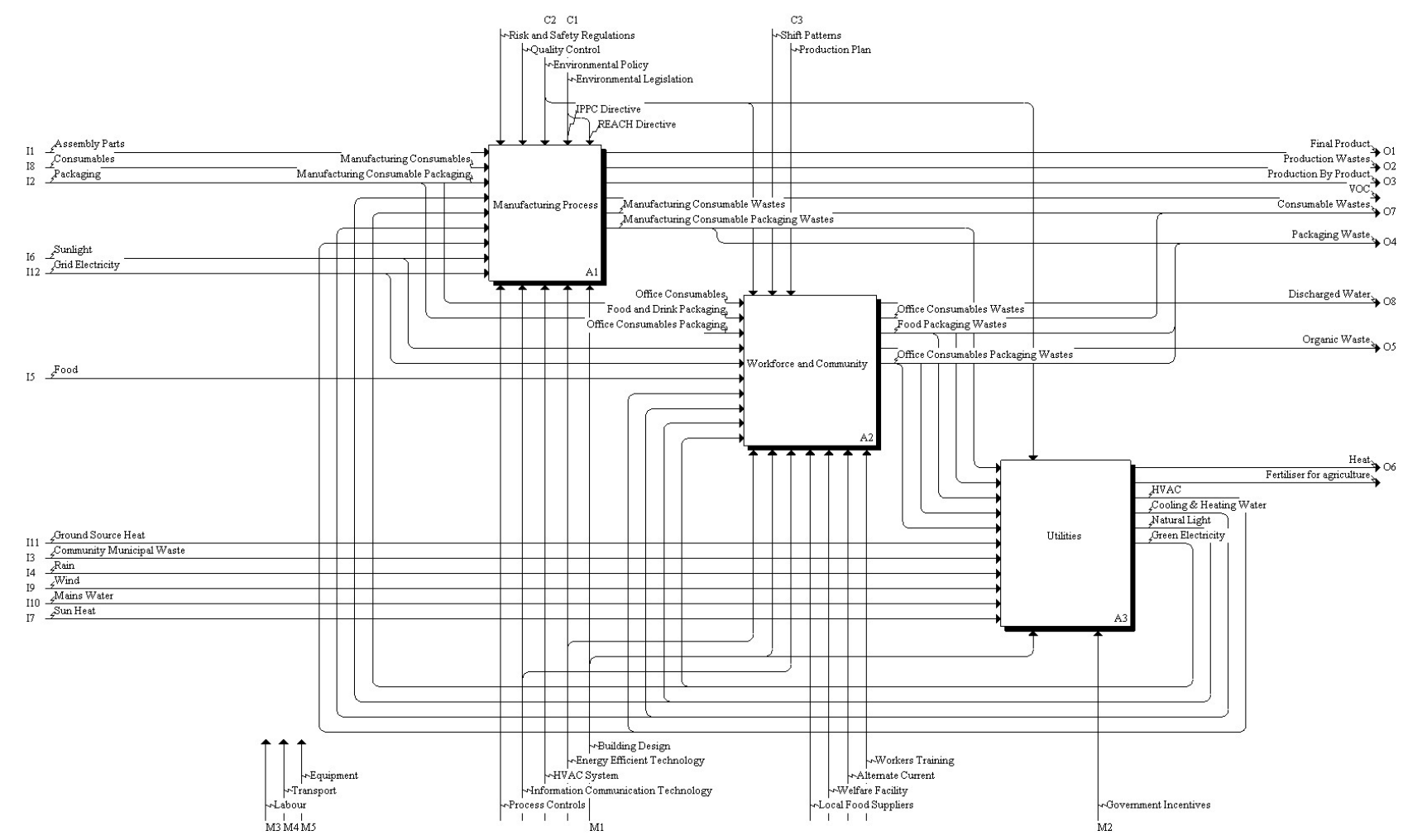

Figure 3. Top level view of the flows of a manufacturing enterprise.

The importance of the modelling approach is that it captures the complexity of manufacturing systems material and energy flows. It can then trigger discussion of how input requirements of one activity can be provided by the output of another activity previously considered independently, e.g. office heating could be provided by excess manufacturing process heat. The controls include legislation and policies. Mechanisms would cover the emerging solutions explained next.

Such maps capture the complexity but it is not suggested they be used in their entirety. When examining a particular flow or area of improvement the relevant flows would be identified and the others discarded. For communication to others, the IDEF0 format could either be maintained or the simplified and represented pictorially. For example, Figure 4 shows the main water flows in a facility. Manufacturing process water flows could be added as appropriate between the membrane bio-reactor and the waste water treatment. The diagram shows how rainwater harvesting from the facility roof is stored, treated, used and then treated for reuse or release into the public sewer. Deliberately, mains water input has not been shown; this diagram is an instance of the IDEF0 flow model from analysis for a UK company to show that it could supply all its water requirements from harvesting and storing less than $25 \%$ of the typical rainwater falling on the roof. This diagram shows how technology and 'know how' can be integrated together in a systems view. Each of these activities can then be costed and compared with current and variant installations. 


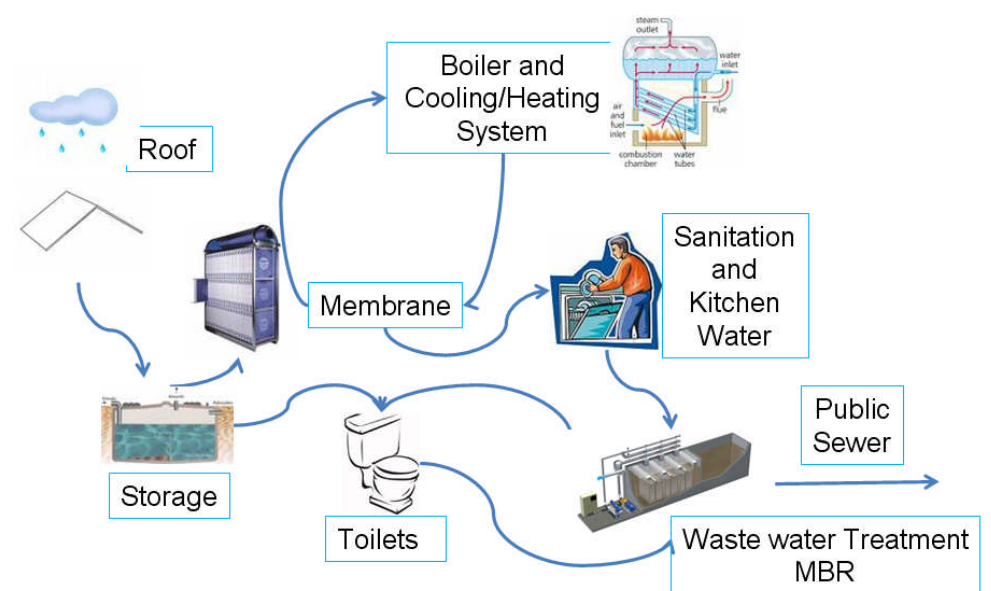

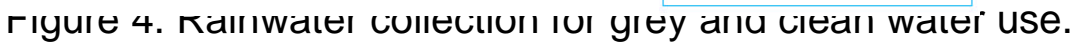

A second example of selecting flows is for the light and heat required for manufacturing operations, illustrated in Figure 5. Again, this is a pictorial representation for a case company taken from the generic flow model shown in Figure 3. Here the material flow is from left to right across the lower part of the diagram and the lighting flows from the use of electricity and solar are shown at the top of the diagram. The particular production process uses a heat treatment operation from which waste heat is captured and transferred for facility heat rather than expelled to the atmosphere. Additionally there is a Combined Heat and Power (CHP) biomass plant that generates heat and electricity for the facility. Whilst this is very much a simplified view, it shows that there is material waste leaving the process that can prompt how this could be reduced or reused. For example, using incoming packaging waste or production waste for the CHP feed. Whilst the supply chain is not represented in the diagram, the embedded carbon in raw materials could be. It would be different for local and global supply and this would impact on the embedded carbon in the finished product. Overall the diagram could be criticised as insufficient representation of the actual system with inputs or outputs missing or under-utilised. However, if such questions arise then the approach serves part of its purpose, namely to trigger discussion and act as a catalyst for ideas. 


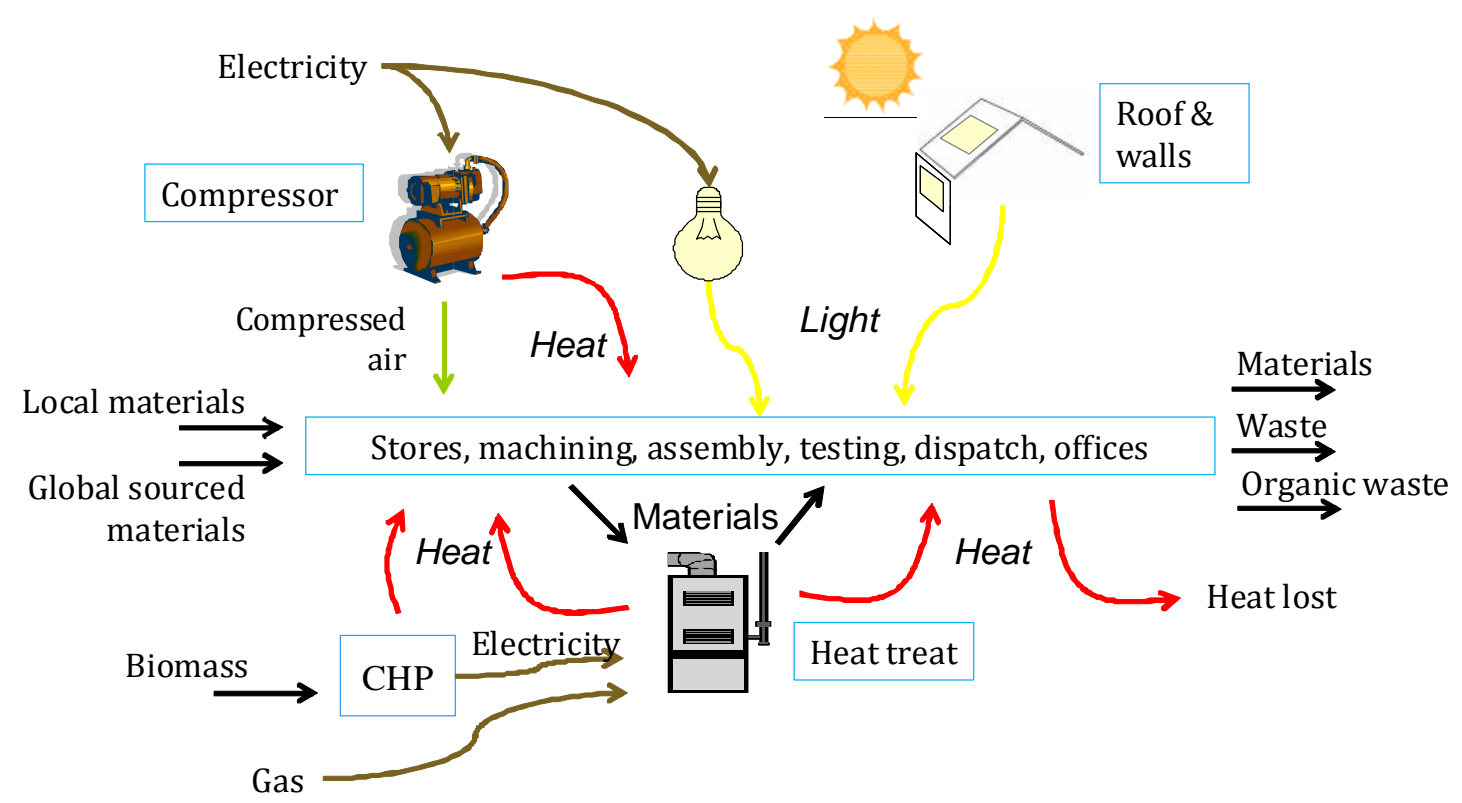

Figure 5. Selected light and heat flows in a manufacturing operation.

A third example shown in figure 6 illustrates selected high level flows for the application of the shot peening (e.g. [37]) process to a typical engineering component. The diagram shows the manufacture of shot, its supply to the component manufacturing facility and its use for shot peening of leaf springs to increase their fatigue life. Shot is created using virgin raw material as well as scrap. The creation of shot and its use in surface treating components is energy intensive and potentially inefficient in its consumption of energy. Once in use however, the treated component has a number of beneficial characteristics compared to an untreated component. These include longer component life, lower component and hence product weight which in turn may result in significant energy savings during the use phase of the product. The balance of energy between the creation and use of the product can be modelled here not just from understanding the energy flows within a facility but also how choices arising from design (material choice based on mechanical properties and the beneficial use of surface treatments to reduce cost and overall energy consumption) and use phase can be accounted for.

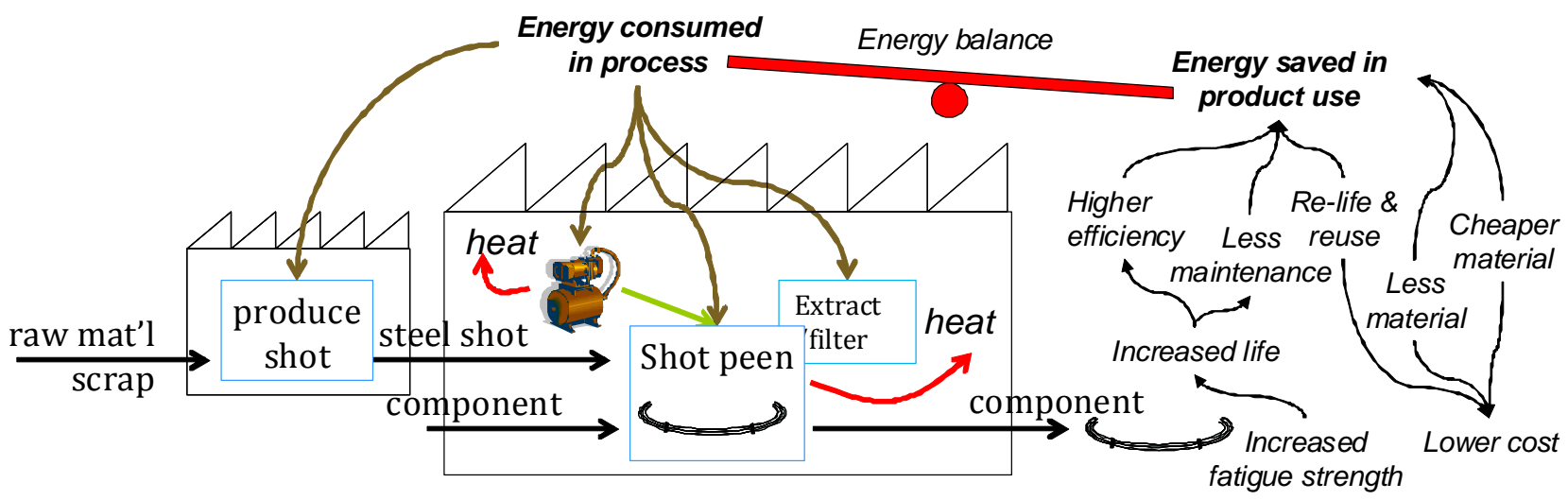

Figure 6. Selected energy flows in the production and use of a shot peened product 
Low and zero carbon technologies provide means of approaching zero carbon manufacture but which technologies should be used? How are these technologies linked together? Integrated, systems thinking approach is essential. Using the material, energy and waste flows of an entire facility, the impact of a technology can be seen in context. This approach moves away from the thinking of utilising clean energy such as a wind turbine as a replacement power source for current demand to thinking in a more integrated way. Taking the water flow in a facility as an example, figure 4 showed how rainwater can be utilised for different facility needs before being cleaned for lower cost entry into the sewer.

The material and energy flows integrate the domains of the facility designers and the process engineers. The flows can be jointly studied by specialists from these two fields to jointly identify waste and opportunities to reduce waste by integrating flows rather than addressing the individual wastes in their respective fields. The examples given are 'instances' of such an integrative discussion taking place between facility and process engineers. Without such maps as a catalyst for ideas and innovation such discussions would not take place.

\section{Challenges ahead}

The awareness of zero carbon and associated technologies is rising fast but approaches to designing, implementing and improving manufacturing and service systems for zero carbon are lagging. Manufacturing and facility engineers seeking to design a zero carbon manufacturing facility are faced with many decisions and many competing technological solutions, often without having deep understanding of the individual solutions. We argue that integration is more important than holding complete knowledge of all candidate technologies. Design and improvement approaches should not be based around technology but should use an integrated systems approach to zero carbon. Such approaches should encourage interdisciplinary working and solutions.

Modelling of the material, energy and waste flows in a single, integrative manner is a start to taking a multidisciplinary, systems approach to designing zero carbon manufacturing systems. By modelling the facility as an integral part of the manufacturing system this approach enables a new set of potential interactions between process and building to be observed, focussing on what is traditionally viewed as waste from one activity to be utilised by another. Generic or process reference models of material, energy and waste flows have the potential to support system design and improvement activities. As a complementary tool they have potential for influencing the creation and evaluation of new designs or improvements.

The modelling approach presented is qualitative and can act as a catalyst for ideas. However, it is not quantitative and therefore does not assess the magnitude, location or quality of the flows. Nor is it dynamic and hence does not represent the timing of flows. The next stage of this research is examining the location, magnitude, quality and timing of the process flows using simulation. Hence making it possible, say, to assess the effectiveness of using large volumes of intermittent warm water from one process as an input to another process elsewhere in a facility.

This paper has shown that generic flows of the pertinent characteristics of a zero carbon manufacturing facility can be modelled, and shown how they can be instantiated around particular technologies. Whilst the generic flows are not a design approach, in the same way 
that other process reference models are not either, they can act as a tool to support the development of a zero carbon manufacturing system. They are helpful in highlighting the need to address the material and energy waste outputs of one activity and to prompt the search for another activity, thus promoting the understanding of the wider lifecycles rather than the functional operation.

Work has started on examining the cost drivers of the material, energy and waste flows but significant further development is needed to capture the full life cost. Ultimately, to be of most benefit, such flow modelling use needs to be guided by revised system design and improvement methodologies. Work is needed on design methodologies that take a wider view of the manufacturing system life cycle and guide the creation of efficient yet low carbon manufacturing systems.

Words $\sim 6,250$.

\section{References}

1 Elkington, J. Cannibals with Forks: The Triple Bottom Line of 21st Century Business, 1998 (New Society Publishers: CT, USA).

2 EEF, UK Steel: Analysis of steel price developments - spring 2008, accessed 18 March 2008, available from http://www.eef.org.uk/NR/rdonlyres/F7254D33-A05A-4D14-8FF7-

BF60654B3D4A/13741/Marketsurvey Mar091.pdf.

3 Defra, Waste strategy factsheets - Landfill Tax, accessed 5 August 2008, available from http://www.defra.gov.uk/environment/waste/strategy/factsheets/landfilltax.htm.

4 RE-KTN, Material Security - Ensuring resource availability for the UK economy (Resource Efficiency Knowledge Transfer Network: Chester).

5 DTI. Review of sustainable construction 2006. URN 06/1734, Pub 8398 (Department of Trade and Industry: London).

6 HM Treasury. Budget 2008 (The Stationery Office: London).

7 Rahimifard, S. and Clegg, A.J. Aspects of sustainable design and manufacture, International Journal of Production Research, 2007, 45(18-19), 4013-4019.

8 Gaughran W.F., Burke S. and Phelan P. Intelligent manufacturing and environmental sustainability, Robotics and Computer-integrated manufacturing, 2007, 23(6), 704-711.

9 Mouzon G., Yildirim M.B., Twomey J. Operational methods for minimization of energy consumption of manufacturing equipment, International Journal of Production Research, 2007, 45(18-19), 4247-4271.

10 Monden, Y. Toyota Production System. An integrated Approach to Just-In-Time, 1994 (Chapman \& Hall: London).

11 Bylinsky G. Manufacturing for reuse: designing products to be torn apart into reusable pieces keeps them greener and can make a profit for practitioners, Fortune, 1995, February, 102-112.

12 Papanek, V. Design For The Real World: Human Ecology And Social Change, 1971 (New York: Pantheon Books)

13 Manzini, E. \& Vezzoli C. A Strategic Design Approach to Develop Sustainable Product Service Systems. Journal of Cleaner Production, 2003, 11(8), 851-857.

14 Ehrenfeld, J. The Roots of Sustainability, Sloan Management Review, 2005, Winter.

15 Ryan C., Climate Change and Ecodesign, Journal of Industrial Ecology, 2008, 12(2), 140-143.

16 Parnaby, J., Concept of a manufacturing system, International Journal of Production Research, 1979, 17(2), 123-135.

17 Hayes, R.H. and Wheelwright, S.C. Restoring our competitive edge: competing through manufacturing, 1984 (Wiley: USA)

18 Bennett, D. Production System Design, 1986 (Butterworth: London).

19 Yin, R. Case study research - design and methods, 1994 (Sage Publications, London).

20 McDonough, W. and Braungart, M. Cradle to Cradle: Remaking the Way We Make Things, 2002 (North Point Press: USA)

21 Bicheno, J. The Lean Toolbox, $2^{\text {nd }}$ Ed 1999 (Picsie Books) 
22 King, A.A. and Lenox, M.J. Lean and green? An empirical examination of the relationship between lean production and environmental performance, Production and Operations Management, 2001, 10(3), 244-256.

23 Carbon Trust, Compressed air - Introducing energy saving opportunities for business, 2007 (Carbon Trust: London).

24 Sarkis, J. A strategic decision framework for green supply chain management, Journal of Cleaner Production, 2003, 11(4), 397-409.

25 Beamon, B.M. Designing the green supply chain, Journal of Enterprise Information Management, 1999, 12(4), 332-342.

26 Walton, S.V., Handfield, R.B. and Melnyk, S.A. The Green Supply Chain: Integrating Suppliers into Environmental Management Processes, International Journal of Purchasing and Materials Management, 1998, 34(2), 1-11.

27 The GreenSCOR Model: Enabling Green Supply Chain Management Through SCOR, accessed 12 August 2008, available from www.supply-chain.org/site/files/Wilkerson_LMI_SCWNA03.pdf

28 Edwards, L. and Torcellini, P. A Literature Review of the Effects of Natural Light on Building Occupants, NREL/TP-550-30769, 2002 (National Renewable Energy Laboratory: Colarado, USA).

29 Carroll, A.B. A Three-dimensional Conceptual Model of Corporate Social Performance, Academy of Management Review, 1979, 4(4), 497-505.

30 Jelinski, L.W., Graedel, T.E., Laudise, R.A., McCall, D.W. and Patel, C.K.N. Industrial Ecology: Concepts and Approaches, Proceedings of the National Academy of Sciences of the United States of America, 1992, 89(3), 793-797.

31 Baines, T.S., Lightfoot, H.W., Evans, S., Neely, A., Greenough, R., Peppard, J., Roy, R., Shehab, E., Braganza, A., Tiwari, A., Alcock, J.R., Angus, J.P., Bastl, M., Cousens, A., Irving, P., Johnson, M., Kingston, J., Lockett, H., Martinez, V., Michele, P., Tranfield, D., Walton, I.M., and Wilson, H. State-of-the-art in product-service systems, Proc. IMechE Part B: J. Engineering Manufacture, 2007, 221, 1543-1552.

32 Westkamper, E., Alting, L. and Arndt, G. Life cycle management and assessment: approaches and visions towards sustainable manufacturing, Proc Instn Mech Engrs Part B - Journal of Engineering Manufacture, 2001, 215(5), 599-626.

33 Geldermann, J., Treitz, M. and Rentz, O. Towards sustainable production networks, International Journal of Production Research, 2007, 45(18-19), 4207-4224.

34 Business in the Community, Toyota Motor Manufacturing (UK) Ltd - recycling waste water using reverse osmosis, accessed 6 August 2008, available from http://www.bitc.org.uk/resources/case_studies/afe_1482_toyota.html.

35 Anon, Immingham blazes the trail, Professional Engineering, 25 June 2008, 4.

36 PCPro, IBM cools data centre with swimming pool, accessed 11 August 2008, available from http://www.pcpro.co.uk/news/184539/ibm-cools-data-centre-with-swimming-pool.html

37 Aggarwal, M.L., Khan, R.A. and Agrawal, V.P. Investigation into the Effects of Shot Peening on the Fretting Fatigue Behaviour of 65Si7 Spring Steel Leaf Springs, Proc. IMechE Part L: J. Materials: Design and Applications, 2005. 219(3), 139-147. 